\title{
Role of Ions in Generation of Taste Nerve Responses to Electrical Tongue Stimulation in Rats
}

\author{
Yuzo Ninomiya and Masaya Funakoshi \\ Department of Oral Physiology, Gifu College of Dentistry, \\ Hozumi, Motosu, Gifu, 501-02 Japan
}

\begin{abstract}
The role of ions in the generation of taste nerve responses to electric currents was studied by examining integrated responses and single fiber discharges of the chorda tympani nerve to chemical and electrical stimulations of the tongue in rats.

Integrated chorda tympani responses to anodal currents were suppressed after cessation of the blood flow to the tongue and on application of $\mathrm{FeCl}_{3}$ to the tongue surface. These findings indicate that electric currents do not stimulate the nerve directly but activate taste cells to evoke neural discharges. Magnitude of the integrated response to anodal current decreased with a decrease in concentration and with an increase in flow rate of the bathing solution applied over the tongue during electrical stimulation. All the chorda tympani fibers responsive to a certain electrolyte responded to anodal or cathodal current in the presence of the same electrolyte at its subliminal concentration in the flow chamber. However, there were a few fibers which did not respond to a few electrolytes, but responded to currents in the presence of either one of the electrolytes even at their much lower concentrations. Across-fiber correlations between the responses to chemical stimuli and anodal currents in the presence of the chemical solutions in the flow chamber indicated that responsiveness to anodal current was not always dependent on species of cation in the bathing solution. From these findings, we assume that the response to electric current is due to the effect of electrophoretically carried ions on not only specific but also non-specific receptor mechanisms for the ions.
\end{abstract}

Electric currents applied to the tongue evoke "electric taste" in man (SUlzER, 1752; ICHIOKA et al., 1963; BUJAS, 1971) and taste nerve responses in vertebrates (Pfaffmann, 1941; Adachi, 1969; Bujas, 1971; Smith and Bealer, 1975; KaShiwayanagi et al., 1979; Yamamoto et al., 1980; Pfaffmann and Pritchard, 1980; NinomiYa and Funakoshi, 1980). However, the mechanism of "electric taste" or genesis of taste nerve response by the current has not been explained satisfactorily. Two hypotheses have been proposed concerning the mechanism

Received for publication February 28, 1981

二宮裕三，船越正也 
of "electric taste": one explains that it results from chemical stimulation of taste receptors by some specific products of electrolysis of the saliva, the extracellular and intracellular fluids, while the other maintains that it is caused by a direct action of the current on either taste cells or taste fibers (BUJAS, 1971). Recent electrophysiological studies in rats (SMITH and BEALER, 1975) and hamsters (PFAFFMANN and PRITCHARD, 1980) have pointed out that chemical action of ions around receptor sites plays a dominant role in the generation of neural responses to electrical stimulation of the tongue. In addition, our previous studies in rats (NINOMIYA and FunAKOSHI, 1980, 1981; NinOMIYA et al., 1981) have suggested that the intrinsic property of individual chorda tympani units would be one of the important factors which determine their responsiveness to electrical stimulation of the tongue.

The present study was performed in the following two ways to clarify the mechanism of generation of taste responses by electric currents. First, in order to determine whether or not electric current applied to the tongue stimulates directly taste cells or taste fibers, integrated rat chorda tympani responses to electric currents were examined before and after cessation of the blood flow to the tongue and administration of $\mathrm{FeCl}_{3}$ to the tongue surface, both of which depress the taste cell responses to chemical stimuli (HelleKant, 1970, 1971; TATEDA and BeIdLER, 1963). Second, to see the effects of ions around receptor sites, integrated nerve responses and single nerve fiber responses to electric currents were examined when solutions containing various kinds of ions at varying concentrations flowed over the tongue during the electrical stimulation. Flow rates of the bathing solutions were also changed in some experiments.

\section{METHODS}

Data were obtained from 57 adult male Wistar rats, ranging in weight from 300 to $500 \mathrm{~g}$. The rat was anesthetized with an intraperitoneal injection of sodium pentobarbital $(50 \mathrm{mg} / \mathrm{kg})$, the trachea was cannulated, and then the rat was fixed in the supine position by the head holder to allow dissection of the chorda tympani nerve. The nerve was exposed, freed from surrounding tissues and cut at the point of entry to the bulla. For whole nerve recording, the entire nerve was placed on an $\mathrm{Ag}-\mathrm{AgCl}$ electrode. A single or a few fibers of the nerve was dissected alive with a pair of needles and lifted on an $\mathrm{Ag}-\mathrm{AgCl}$ electrode. In both experiments, an indifferent electrode was positioned nearby in the wound. Neural responses resulting from chemical and electrical stimulations of the tongue were fed into an amplifier (Nihon Kohden MZ-4) and displayed on an oscilloscope screen (Nihon Kohden VC-7). Whole nerve responses were integrated and displayed on a stripchart recorder. The time constant of the integrator used was 100 msec. Impulse discharge of single fibers were photographed.

For the experiment to examine the effect of cessation of blood flow to the tongue, an external carotid artery, which was ipsilateral to the dissected chorda 
tympani nerve, was clamped at a point proximal to the branching of the lingual artery.

The anterior half of the rat's tongue was enclosed in a flow chamber made of silicone rubber. Solutions were delivered into the flow chamber through magnetic valves and input tubes by gravity flow, and flowed over the tongue for a controlled period. Switching of magnetic valves was controlled by "Taste-o-matic" (HelleKant et al., 1980). Sequences of chemical stimulations were set by a builtin programming device in this system. A stimulating $\mathrm{Ag}-\mathrm{AgCl}$ electrode was placed on the inside wall of the flow chamber but was sometimes placed directly on the tongue when required, while an $\mathrm{Ag}-\mathrm{AgCl}$ indifferent electrode was positioned nearby in the wound around the neck.

Electrical stimulation of the tongue was given by means of a Trapezoid Generator (Dia-medical, Tokyo, Japan). A resistance ranging from 1 to $5 \mathrm{M} \Omega$ was put in series between the stimulating electrode and the stimulator to avoid fluctuation of the current level. Current intensity used was varied from 5 to $50 \mu \mathrm{A}$. The rate of current rise used was fixed at $100 \mu \mathrm{A} / \mathrm{sec}$. Duration of currents was about $10 \mathrm{sec}$. Current intensity was monitored with a milliammeter, displayed on an oscilloscope and photographed during the experiment.

Solutions used as chemical stimuli were $0.1 \mathrm{M} \mathrm{NaCl}, 0.1 \mathrm{M} \mathrm{KCl}, 0.1 \mathrm{M} \mathrm{CaCl}_{2}$, $0.01 \mathrm{M} \mathrm{HCl}, 0.5 \mathrm{~m}$ sucrose, $0.02 \mathrm{~m}$ saccharin $\mathrm{Na}$, and $0.02 \mathrm{M}$ quinine hydrochloride, while those used as bathing media flowing over the tongue during electrical srimulation were $0.00003 \mathrm{M}, 0.0001 \mathrm{M}, 0.0003 \mathrm{M}$ and $0.001 \mathrm{M} \mathrm{NaCl}, 0.001 \mathrm{M} \mathrm{KCl}, 0.001 \mathrm{M}$ $\mathrm{CaCl}_{2}, 0.0001 \mathrm{M} \mathrm{HCl}, 0.0002 \mathrm{~m}$ saccharin $\mathrm{Na}, 0.0002 \mathrm{M}$ quinine hydrochloride, and distilled water (conductivity $\leqq 4.0 \times 10^{7} \mho / \mathrm{cm}$ ). These solutions were made up in distilled water at about $20^{\circ} \mathrm{C}$. For cold stimulation of the tongue, distilled water at about $5^{\circ} \mathrm{C}$ was used. During chemical stimulation of the tongue, test solutions were flowed at the same flow rate as the distilled water used for rising the tongue $(2.5 \mathrm{ml} / \mathrm{sec})$. The tongue was continuously rinsed during the entire interval between successive stimulations, which was taken at more than 1 min to avoid possible after-effects of the preceding stimulus (Hellekant, 1968). For electrical stimulation of the tongue, the rat's tongue was pre-adapted to the bathing solution for more than $1 \mathrm{~min}$ prior to the stimulation by introducing the solution in the flow chamber. During the stimulation, the bathing solution was flowed at various rates ranging from 0 to $3.0 \mathrm{ml} / \mathrm{sec}$. Different flow rates were obtained by applying different strengths of clamp to the input tube. In the case of $0 \mathrm{ml} /$ sec flow rate, its outlet was completely closed by clamping and the flow chamber was filled with a solution. In single fiber experiments, response to electric currents were examined using a fixed flow rate $(2.5 \mathrm{ml} / \mathrm{sec})$ of bathing solution, the same rate as that for chemical stimulation. 


\section{RESULTS}

Effects of cessation of the blood flow on taste nerve responses

Figure 1 shows the effect of occlusion of the ipsilateral external carotid artery on the integrated chorda tympani response to anodal current applied to the tongue. The artery was occluded proximally to its branching of the lingual artery. The stimulating electrode was put directly on the tongue surface. Anodal current with a rise rate of $100 \mu \mathrm{A} / \mathrm{sec}$ produced an initial transient, and a following steady response (Fig. 1-upper trace). The integrated response diminished within a few min after cessation of the blood flow to the tongue, and returned to the original magnitude when occlusion was removed. Such an effect of occlusion was found in the whole range of current intensities used in the present study, even when the stimulating electrode was dipped in bathing chemical solutions flowing over the tongue during stimulation.

\section{Effects of application of $\mathrm{FeCl}_{3}$ on taste nerve responses}

$\mathrm{FeCl}_{3}$, which depolarizes the membrane potential of the taste cell and has a depressing effect on chorda tympani responses to chemical stimuli (TATEDA and BEIDLER, 1963), was applied to the tongue surface. As shown in Fig. 2, application of $0.01 \mathrm{M} \mathrm{FeCl}_{3}$ abolished responses to anodal currents of 10 and $20 \mu \mathrm{A}$ intensity, and decreased that of $30 \mu \mathrm{A}$. When $0.06 \mathrm{M} \mathrm{FeCl}_{3}$ was used, responses to anodal currents of the above three different intensities disappeared completely, although $0.06 \mathrm{M} \mathrm{FeCl}_{3}$ in itself produced greater neural activity than did $0.01 \mathrm{M}$ $\mathrm{FeCl}_{3}$. These depressing effects of $\mathrm{FeCl}_{3}$ on responses to anodal currents were observed in all 6 experiments. In one special case, anodal currents produced lowering of the base line activity of integrated response after $0.06 \mathrm{M} \mathrm{FeCl}_{3}$.

Effects of flow of various chemical solutions on taste nerve responses

Figure 3 shows sample records of responses to $0.1 \mathrm{M} \mathrm{NaCl}, \mathrm{KCl}$, and anodal currents in the presence of either $\mathrm{NaCl}$ or $\mathrm{KCl}$ in the flow chamber. The magnitude of the steady phase of response to $0.1 \mathrm{M} \mathrm{NaCl}$ was about twice that to $0.1 \mathrm{M}$ $\mathrm{KCl}$, which is consistent with the previous findings (BEIDLER et al., 1955). Additionally, anodal current stimulation with $0.001 \mathrm{M} \mathrm{NaCl}$ present in the flow chamber always produced larger responses than that elicited by the same current intensity with $0.001 \mathrm{M} \mathrm{KCl}$. As shown in Fig. 4, the mean value of the relative

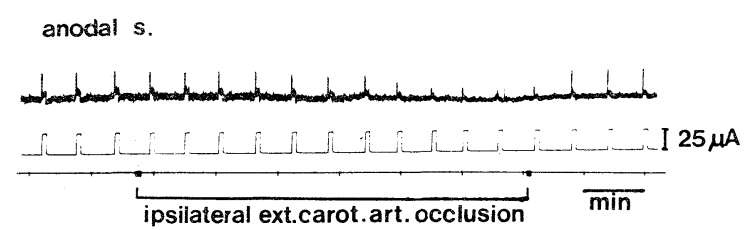

Fig. 1. Suppressive effects of occlusion of external carotid artery on integrated rat chorda tympani responses to repeated applications of anodal current to the tongue. 


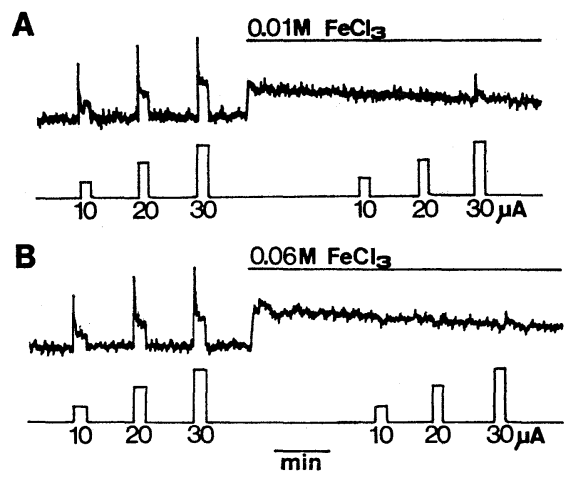

Fig. 2. Integrated rat chorda tympani responses to anodal currents of various intensities applied to the tongue before and after application of $0.01 \mathrm{M}(\mathrm{A})$ and $0.06 \mathrm{M} \mathrm{FeCl}_{3}$ (B) to the tongue surface. Each record was obtained from a separate rat.

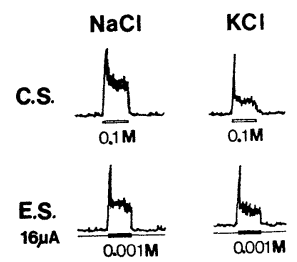

Fig. 3. Integrated rat chorda tympani responses to chemical (C.S.) and electrical (E.S.) stimulations of the tongue. Chemical stimuli used were $0.1 \mathrm{M}$ $\mathrm{NaCl}$ and $\mathrm{KCl}$. Anodal currents were applied to the tongue in the presence of $0.001 \mathrm{M} \mathrm{NaCl}$ or $\mathrm{KCl}$ in the flow chamber.

magnitude of response to anodal current with $0.001 \mathrm{M} \mathrm{NaCl}$ calculated from 4 rats was 2.4, when the response magnitude for the same current with distilled water present was taken as unity, while that with $0.001 \mathrm{M} \mathrm{KCl}$ was 1.7. Although anodal currents produced a response when distilled water was flowed over the tongure in the chamber, in this case a much higher voltage was needed to elicit a response than that with $0.001 \mathrm{M} \mathrm{NaCl}$ or $\mathrm{KCl}$. The magnitude of the response decreased with increasing flow rate of distilled water, and it reached a minimum at about $1.5 \mathrm{ml} / \mathrm{sec}$. In spite of further increase in the flow rate, the magnitude was nearly the same (Fig. 4). Such dependency on flow rate of response magnitude to anodal current was also observed in the cases when $0.001 \mathrm{M} \mathrm{NaCl}$ or $\mathrm{KCl}$ was employed as a bathing medium.

Figure 5 shows a relative magnitude of response to anodal current as a function of concentration of $\mathrm{NaCl}$ in a bathing medium. Magnitudes of the transient and steady responses decreased with decrease in concentration of $\mathrm{NaCl}$ from 0.001 to $0.00003 \mathrm{M}$, although current intensity was constant. From these results, it is suggested that the response to anodal current is influenced by ions present between the stimulating electrode and the mucous membrane of the tongue.

Relationship between responses to electrical and chemical stimulations of the tongue

In order to see the relationship between the responses to electrical and chemi- 


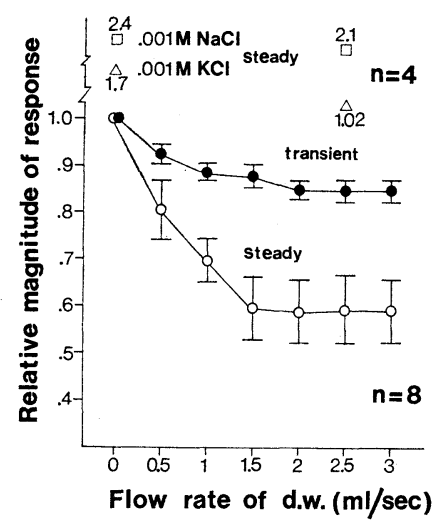

Fig. 4. Relative magnitude of the integrated rat chorda tympani response to anodal current as a function of rate of flow distilled water over the tongue. Each point represents the mean magnitude of transient response $(\bullet)$ and steady-state response $(O)$ obtained from 8 rats. Current intensity used was $10 \mu \mathrm{A}$. Vertical bars show \pm S.D. As comparisons, the mean relative magnitudes of steady-state response to anodal current in the presence of $0.001 \mathrm{M} \mathrm{NaCl}(\square)$ or $0.001 \mathrm{M} \mathrm{KCl}(\triangle)$ in the flow chamber obtained from 4 rats are also presented in the upper side of this figure.

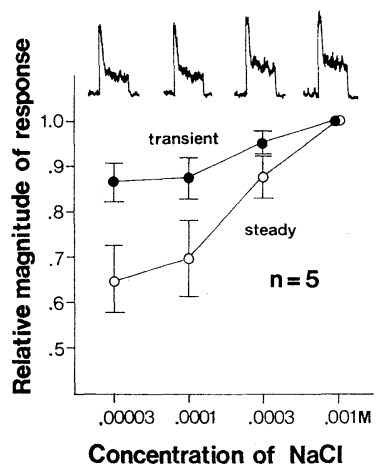

Fig. 5. Relative magnitude of the integrated rat chorda tympani response to anodal current as a function of concentration of $\mathrm{NaCl}$ in the flow chamber. Each point represents the mean magnitude of transient response $(\bullet)$ and steady-state response $(O)$ obtained from 5 rats. Current intensity used was $10 \mu \mathrm{A}$. Vertical bars show \pm S.D.

cal stimulations, responses of 25 single chorda tympani fibers to electrical stimulations were examined by using 7 different bathing solutions and 7 different chemical stimuli. During stimulation, the solutions were flowed over the tongue at a rate of $2.5 \mathrm{ml} / \mathrm{sec}$. Intensities of anodal and cathodal currents used were +10 and $-10 \mu \mathrm{A}$, respectively.

Being consistent with our previous findings (NINOMIYA and FunAKOSHI, 1980, 1981), chorda tympani fibers were classified into three types according to their response patterns to anodal and cathodal currents. Twenty out of 25 fibers re- 
sponded only to anodal current (Type A fibers), 3 fibers to both anodal and cathodal currents (Type B fibers), and the remaining 2 fibers only to cathodal current (Type $\mathrm{C}$ fibers). In all 25 fibers, the rate of impulse discharges to electric current varied with varying bathing media. Variations in discharge rates were also found among various chemical stimuli. In general, it was found that all fibers sensitive to a certain electrolytic chemical stimulus always responded to anodal or cathodal current in the presence of the same electrolyte at its subliminal concentration in the flow chamber. For each fiber, ions which were most effective in facilitating the response to electrical stimulation were also found most effective as chemical stimuli themselves. On the other hand, a few fibers existed which did not respond to a few electrolytic chemical stimuli, but responded to currents in the presence of either one of the same electrolytes at very low concentrations in the flow chamber. For example, the fiber illustrated in Fig. 6 was sensitive to $0.1 \mathrm{M} \mathrm{NaCl}$, but not to $0.1 \mathrm{M} \mathrm{KCl}$ and $0.01 \mathrm{M} \mathrm{HCl}$, although it responded to anodal current stimulations in the presence of either $0.001 \mathrm{M} \mathrm{NaCl}, 0.001 \mathrm{M}$ $\mathrm{KCl}$, or $0.0001 \mathrm{M} \mathrm{HCl}$ in the flow chamber. Figure 7 shows another example of the fiber, which responded well to $0.02 \mathrm{M}$ quinine hydrochloride, $0.02 \mathrm{M}$ saccharin $\mathrm{Na}$ and $0.5 \mathrm{M}$ sucrose, and slightly to $0.1 \mathrm{M} \mathrm{CaCl}_{2}$, but not to $0.1 \mathrm{M} \mathrm{NaCl}$, $0.1 \mathrm{M} \mathrm{KCl}, 0.01 \mathrm{M} \mathrm{HCl}$ nor cooling of the tongue. This fiber responded to cathodal current in the presence of any one of the 7 different solutions at their subliminal concentrations in the flow chamber, although the discharge rates to the current varied among the solutions.

It has been proposed that the quality of the stimulus is coded by the response pattern across many neurons. The similarity or dissimilarity of pairs of response profiles can be represented by the correlation coefficient of the number of impulses per unit time across neurons (ERICKSON, 1963; ERICKSON et al., 1965; GANCHROW and ERICKSON, 1970). Thus, correlation coefficients between the amounts of responses to chemical, electrical and cold stimulations of the tongue were calculated

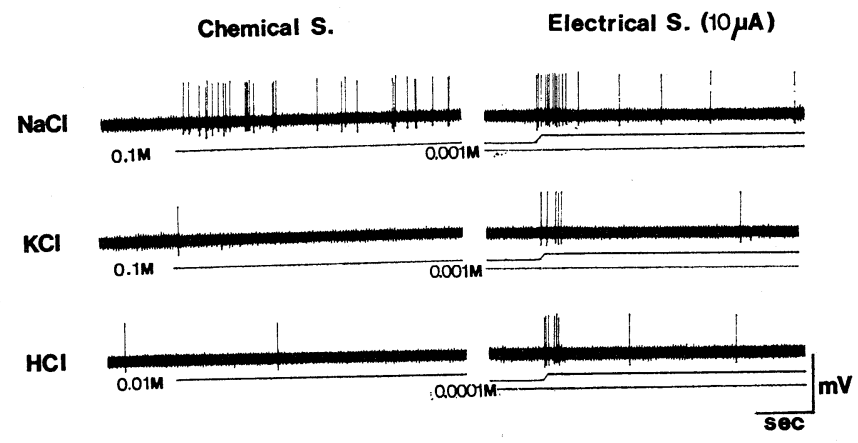

Fig. 6. Responses of a single rat chorda tympani fiber to chemical and electrical stimulations of the tongue. Chemical stimuli used were $0.1 \mathrm{M} \mathrm{NaCl}, 0.1 \mathrm{M} \mathrm{KCl}$, and $0.01 \mathrm{M} \mathrm{HCl}$. Anodal currents were applied to the tongue in the presence of $0.001 \mathrm{M} \mathrm{NaCl}, 0.001 \mathrm{M}$ $\mathrm{KCl}$, or $0.0001 \mathrm{M} \mathrm{HCl}$ in the flow chamber. Current intensity used was $10 \mu \mathrm{A}$. 


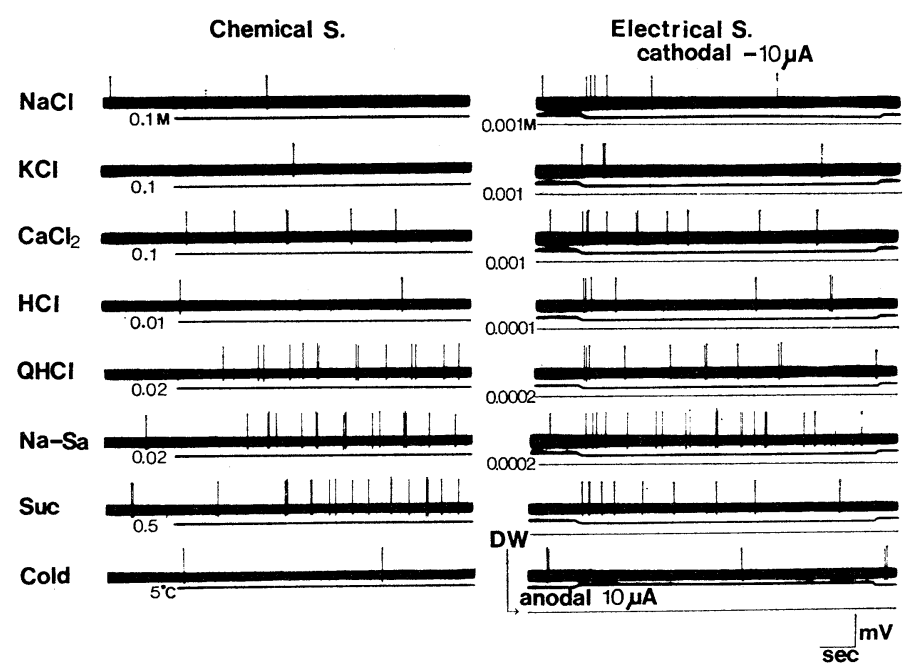

Fig. 7. Responses of a single rat chorda tympani fiber to chemical and electrical stimulations of the tongue. Chemical stimuli used were $0.1 \mathrm{M} \mathrm{NaCl}, 0.1 \mathrm{M} \mathrm{KCl}, 0.1 \mathrm{M} \mathrm{CaCl}_{2}, 0.01 \mathrm{M} \mathrm{HCl}$, $0.02 \mathrm{M}$ quinine hydrochloride, $0.02 \mathrm{M}$ saccharin $\mathrm{Na}$, and $0.5 \mathrm{M}$ sucrose. Cathodal currents of $-10 \mu \mathrm{A}$ in intensity were applied to the tongue in the presence of $0.001 \mathrm{M} \mathrm{NaCl}, 0.001$ $\mathrm{M} \mathrm{KCl}, 0.001 \mathrm{M} \mathrm{CaCl}_{2}, 0.0001 \mathrm{M} \mathrm{HCl}, 0.0002 \mathrm{M}$ quinine hydrochloride, $0.0002 \mathrm{M}$ saccharin $\mathrm{Na}$, or distilled water in the flow chamber. The bottom record of the right hand column presents effect of anodal current of $10 \mu \mathrm{A}$ applied in the presence of distilled water.

for the 23 chorda tympani fibers responding to anodal current (20 type A fibers and 3 type B fibers). Calculations were based on the number of impulses for the first $5 \mathrm{sec}$ after stimulus onset. As shown in Table 1, correlation coefficients between the amounts of responses to $0.1 \mathrm{M} \mathrm{CaCl}_{2}$ and to anodal current in the presence of $0.001 \mathrm{M} \mathrm{CaCl}_{2}$ in the flow chamber was 0.645 , and those to $0.01 \mathrm{M} \mathrm{HCl}$ and to anodal current in the presence of $0.0001 \mathrm{M} \mathrm{HCl}$ was 0.657 . This indicates that these pairs of stimuli produced similar neural patterns. On the other hand, the correlation coefficient between responses to $0.1 \mathrm{M} \mathrm{KCl}$ and to anodal current in the presence of $0.001 \mathrm{M} \mathrm{KCl}$ in the flow chamber was 0.345 , indicating no significant similarity between the two neural patterns. These results may suggest that responsiveness to anodal current was not always dependent on species of cation in the bathing solution used.

Table 2 shows the correlation coefficient between each pair of response profiles for 4 different chemical stimuli (c.s.), and between that for anodal currents with each of 5 different bathing solutions present in the flow chamber (e.s.). In this table, discrepancy of correlations between responses to electrical stimulation with different bathing media from those for chemical stimulations were observed in the stimulus pairs of $\mathrm{HCl}$ and $\mathrm{NaCl}$ (e.s., 0.731 ; c.s., 0.145 ), $\mathrm{CaCl}_{2}$ and $\mathrm{NaCl}$ (e.s., 0.742; c.s., 0.290), and $\mathrm{KCl}$ and $\mathrm{NaCl}$ (e.s., 0.523; c.s., 0.222). These results 
Table 1. Correlations between single chorda tympani fiber responses to chemical, electrical, and thermal stimulations of the tongue.

\begin{tabular}{rcccccc}
\hline \multicolumn{5}{c}{ Clod and chemical stimuli } & & \multicolumn{2}{c}{$\begin{array}{c}\text { Bathing solutions used } \\
\text { for electrical stimula- } \\
\text { tion }(+10 \mu \mathrm{A})\end{array}$} \\
\hline 0.027 & $0.435^{*}$ & 0.388 & 0.258 & $\underline{0.467^{*}}$ & $0.001 \mathrm{M} \mathrm{NaCl}$ \\
0.230 & $0.507^{*}$ & $0.459^{*}$ & $\underline{0.345}$ & 0.033 & $0.001 \mathrm{M} \mathrm{KCl}$ \\
0.192 & $0.588^{* *}$ & $0.645^{* *}$ & $0.479^{*}$ & 0.285 & $0.001 \mathrm{M} \mathrm{CaCl}_{2}$ \\
-0.050 & $0.657^{* *}$ & $0.536^{*}$ & $0.448^{*}$ & 0.222 & $0.0001 \mathrm{M} \mathrm{HCl}$ \\
0.073 & $0.437^{*}$ & $0.457^{*}$ & 0.265 & $0.454^{*}$ & D.W. \\
\hline
\end{tabular}

Significant levels of correlation coefficients: $* 0.01<p<0.05$; $* * 0.001<p<0.01$; $* * *$ $p<0.001(n=23)$.

Table 2. Correlations between single chorda tympani fiber responses to pairs of stimuli in chemical and electrical stimulations of the tongue.

\begin{tabular}{|c|c|c|c|c|c|}
\hline $\mathrm{KCl}$ & $\mathrm{CaCl}_{2}$ & $\mathrm{HCl}$ & D.W. & & \\
\hline $0.523^{*}$ & $0.742 * * *$ & $0.731^{* * *}$ & $0.851 * * *$ & e.s. & $\mathrm{NaCl}$ \\
\hline \multirow[t]{6}{*}{0.222} & 0.290 & 0.145 & & c.s. & \\
\hline & $0.791 * * *$ & $0.675^{* * *}$ & $0.634 * *$ & e.s. & $\mathrm{KCl}$ \\
\hline & $0.751^{* * *}$ & $0.618 * *$ & & c.s. & \\
\hline & & $0.772 * * *$ & $0.765^{* * *}$ & e.s. & $\mathrm{CaCl}_{2}$ \\
\hline & & $0.714^{* * *}$ & & c.s. & \\
\hline & & & $0.739 * * *$ & e.s. & $\mathrm{HCl}$ \\
\hline
\end{tabular}

Significant levels of correlation coefficients: $* 0.01<p<0.05 ; * * 0.001<p<0.01$; $* * * p<0.001(n=23)$. e.s.: electrical stimulation with bathing solution. Bathing solutions used were $0.001 \mathrm{M} \mathrm{NaCl}, 0.001 \mathrm{M} \mathrm{KCl}, 0.001 \mathrm{M} \mathrm{CaCl}_{2}, 0.0001 \mathrm{M} \mathrm{HCl}$, and distilled water. c.s.: chemical stimulation. Chemical stimuli used were $0.1 \mathrm{M} \mathrm{NaCl}, 0.1 \mathrm{M} \mathrm{KCl}$, $0.1 \mathrm{M} \mathrm{CaCl}_{2}$, and $0.01 \mathrm{M} \mathrm{HCl}$.

may indicate that ion specificity in response to electrical stimulation was considerably lower than that in response to chemical stimuli.

\section{DISCUSSION}

Hellekant $(1970,1971)$ first observed that cessation of the blood flow to the tongue abolished the rat chorda tympani responses to chemical stimuli within a few min. He suggested that the effects of occlusion of the blood supply on taste responses were attributed to a decrease in activity of taste cells caused by their lowered metabolic rates during arrest of circulation, but not to changes of the conductivity and excitability of the fibers which remain unchanged for a much longer time than that described above. In the present study, similar effects of occlusion were observed in responses to anodal currents. TATEDA and BEIDLER (1963) reported that $\mathrm{FeCl}_{3}$ applied to the rat's tongue surface depolarized mem- 
brane potentials of taste cells and depressed responses of taste cells to chemical stimuli, and that the magnitude of response of taste cells to $1.0 \mathrm{M}$ or $0.25 \mathrm{M} \mathrm{NaCl}$ decreased with an increase in magnitude of depolarization of taste cells produced by $\mathrm{FeCl}_{3}$. We found that integrated responses of the rat chorda tympani nerve to anodal currents were also depressed after application of $\mathrm{FeCl}_{3}$ to the tongue surface, and these depressing effects appeared more prominently with greater magnitude of positive deflection of baseline activity of the integrated response produced by $\mathrm{FeCl}_{3}$. These observations indicate that anodal current does not stimulate chorda tympani fibers directly, but affects taste receptor cells. Concerning the action of cathodal current, however, BuJAs (1971) has suggested that it probably provokes a response in the taste nerve by directly affecting taste cells or fibers. In the present experiments, cathodal current applied to the tongue generally suppressed the spontaneous activity of the rat chorda tympani nerve even when a current intensity of $50 \mu \mathrm{A}$ was used with various bathing solutions, and only a few chorda tympani fibers responded to cathodal current. These observations may reject the possibility that cathodal currents of $50 \mu \mathrm{A}$ or less in intensity could directly and non-selectively activate taste cells or fibers.

The present study revealed that responses to anodal currents were affected by the kind, concentration, and flow rate of the solution over the tongue surface. In this experiment, an anodal current of $10 \mu \mathrm{A}$ intensity produced a response even when distilled water was passed over the tongue at high flow rates. This means that a small amount of ions still exists in the space between the stimulating electrode and the tongue, most probably the microvilli membrane, and such a small amount of ions would be enough for the generation of response to the current obtained by very high stimulus voltage. SMITH and BEALER (1975) suggested that the response of the rat chorda tympani nerve to anodal current was due to chemical action of cations accumulated around the receptor membrane. Since lowering of the concentration of $\mathrm{NaCl}$ or increase of the flow rate of distilled water in the flow chamber, which may decrease probability of accumulation of cations, decreased magnitude of response to anodal current, we concluded that the accumulation of cations is certainly one of the factors responsible for the response to anodal current.

Pfaffmann and Pritchard (1980) reported that exclusively sweet-sensitive chorda tympani fibers of the hamster responded to cathodal current but not to anodal current, while $\mathrm{NaCl}$ - or salt-acid-sensitive but sucrose-insensitive fibers responded only to anodal current. Thus, they proposed an ion binding specificity hypothesis that anodal current forces salt- or electrolyte-sensitive receptor elements to bind with iontophoretically carried cations, while cathodal current stimulates the sweet receptors by iontophoresis of anions. Our results showed that a fiber sensitive to $0.02 \mathrm{M}$ saccharin $\mathrm{Na}$ and $0.5 \mathrm{M}$ sucrose responded to cathodal current in the presence of $0.0002 \mathrm{M}$ saccharin $\mathrm{Na}$ in the flow chamber, and fibers sensitive to a certain electrolytic chemical stimulus always responded to 
anodal current in the presence of the same electrolyte at its subliminal concentration in the flow chamber. These facts may support their idea. However, the ion binding specificity hypothesis cannot explain the following findings satisfactorily. 1) There are a few fibers which did not respond to a certain few electrolytic chemical stimuli, but responded to currents in the presence of any one of the same electrolytes at very low concentrations in the flow chamber (Figs. 6 and 7). 2) Across-fiber correlations between responses to chemical and electrical stimulations with the same cations present are not always high (Table 1). 3) Across-fiber correlations between various stimulus pairs for electrical stimulation are high as compared with those for chemical stimulation (Table 2).

Taking into consideration the above results, we speculate a possible receptor mechanism for the response of the chorda tympani nerve to electric currents. When anodal or cathodal current is applied to the tongue, ions (cations or anions) in the fluid on the tongue are electrophoretically carried to the taste receptor cell membrane, and then interact with not only specific receptor mechanisms for ions but also receptor mechanisms for other kinds of stimuli modifying the electrical field around the receptor membrane. The ease or difficulty of the interaction with the other type of receptor mechanism would vary with species of ions according to their physical and electrical properties. For example, $\mathrm{K}^{+}$could affect not only the $\mathrm{K}^{+}$-specific receptor mechanism but also those for $\mathrm{H}^{+}, \mathrm{Ca}^{2+}$, and so on.

Since the rat taste cell itself can be depolarized by the application of a salt at a very low concentration to the tongue which does not produce impulses in the taste nerve (OzEKI and SATO, 1972), it is possible that any electrolyte at its subliminal concentration applied to the tongue before electrical stimulation affects the electric charge or permeability of any taste cell membrane non-specifically, which may modify the responsiveness of taste cells to electric currents. In order to examine this possibility, however, examination of potential changes in taste cell membranes produced by applications of chemical and electrical stimuli to the tongue are needed.

This work was supported in part by Grant-in-Aid for Scientific Research (No. 477789) from the Ministry of Education, Science and Culture of Japan.

\section{REFERENCES}

AdACHI, A. (1969) Responses of the chorda tympani to electrotonic, electrolytic, and nonelectrolytic stimulations on the tongue. In: Olfaction and Taste, Vol. 3, ed. by Pfaffman, C. The Rockefeller University Press, New York, p. 611.

Beidler, L. M., Fishman, I. Y., and Hardiman, C. W. (1955) Species differences in taste responses. Am. J. Physiol., 181: 235-239.

Bujas, Z. (1971) Electric taste. In: Handbook of Sensory Physiology, 4, Chemical Senses, Pt. 2, Taste, ed. by BeIdLer, L. M. Springer-Verlag, Berlin, pp. 180-199.

ERICKSON, R. P. (1963) Sensory neural patterns and gustation. In: Olfaction and Taste, Vol. 1, ed. by Zotterman, Y. Pergamon Press, Oxford, pp. 205-213.

Vol. 31, No. 6, 1981 
ERICKson, R. P., Doetsch, G. S., and Marshall, D. (1965) The gustatory neural response function. J. Gen. Physiol., 49: 247-263.

Ganchrow, J. R. and ERICKson, R. P. (1970) Neural correlates of gustatory intensity and quality. J. Neurophysiol., 33: 768-783.

Hellekant, G. (1968) Postexcitatory depression of gustatory receptors. Acta Physiol. Scand., 74: $1-9$.

Hellekant, G. (1970) The influence of the circulation on taste receptors as shown by the summated chorda tympani nerve response in the rat. In: Ciba Foundation Symposium on Taste and Smell in Vertebrates, ed. by Wolstenholme, G. E. W. and Knight, J. J. and A. Churchill, London, pp. 83-97.

HelleKant, G. (1971) The effect of changes in the blood flow to the tongue on the chorda tympani response in rat. Acta Physiol. Scand., 82: 145-153.

Hellekant, G., Aronsson, T., and Carlbom, U. (1980) Taste-o-matic: An advanced device for taste stimulation. In: Olfaction and Taste, Vol. 7, ed. by VAN DER StARRe, H. IRL Press, London, p. 203.

IchiokA, M., OHвA, A., and Shimizu, H. (1963) Versuche über den elektrischen Geschmack. Z. Biol., 113: 461-471.

Kashiwayanagi, M., Yoshi, K., Kamo, N., Kurihara, K., and Kobatake, Y. (1979) Electrical stimulation as a tool for elucidating the gustatory receptor mechanism. In: Proceedings of the 13th Japanese Symposium on Taste and Smell, ed. by Funakoshi, M. Gifu College of Dentistry, Gifu, p. 102.

NinomiYa, Y. and Funakoshi, M. (1980) Responses of the rat chorda tympani fibers to electric current of varying rate of rise applied to the tongue. In: Olfaction and Taste, Vol. 7, ed. by VAN DER STARRE, H. IRL Press, London, p. 217.

NinomiYa, Y. and Funakoshi, M. (1981) Responses of rat chorda tympani fibers to electrical stimulation of the tongue. Jpn. J. Physiol., 31: 559-570.

Ninomiya, Y., Mizukoshi, T., and Funakoshi, M. (1981) Dynamic-static sensitivity of rat chorda tympani fibers to anodal current applied to the tongue. Brain Res., 214: 190-195.

OzeKI, M. and SATO, M. (1972) Responses of gustatory cells in the tongue of rat to stimuli representing four taste qualities. Comp. Biochem. Physiol. (A), 41: 391-407.

Pfaffmann, C. (1941) Gustatory afferent impulses. J. Cell. Comp. Physiol., 17: 243-258.

Pfaffmann, C. and Pritchard, T. (1980) Ion specificity of "Electric Taste." In: Olfaction and Taste, Vol. 7, ed. by van DeR StARre, H. IRL Press, London, pp. 175-178.

SMITH, D. V. and BEALER, S. L. (1975) Sensitivity of the rat gustatory system to the rate of stimulus onset. Physiol. Behav., 15: 303-314.

SUlZER, M. (1752) Recherches sur l'origine des sentiments agréables et desagréables. Troisième partie: Des plaisirs des sens. Historie de l'académie des sciences et belles lettres de Berlin. Quoted from; Bujas, Z. (1971) Electric taste. In: Handbook of Sensory Physiology, 4, Chemical Senses, Pt. 2, Taste, ed. by BeIDler, L. M. Springer-Verlag, Berlin, pp. 180-199.

TAteda, H. and Beidler, L. M. (1963) The receptor potential of the taste cell of the rat. J. Gen. Physiol., 47: 479-486.

Yamamoto, T., Yuyama, N., and Kawamura, Y. (1980) Responses of cortical taste cells and chorda tympani fibers to anodal D.C. stimulation of the tongue in rats. Exp. Brain Res., 40: $63-70$. 